\title{
Induction of Cell Cycle Progression by Hepatitis B Virus HBx Gene Expression in Quiescent Mouse Fibroblasts
}

\author{
Kazuhiko Koike, ${ }^{*}$ Kyoji Moriya, ${ }^{*}$ Hiroshi Yotsuyanagi, * Shiro lino, ${ }^{\star}$ and Kiyoshi Kurokawa \\ * First Department of Internal Medicine, University of Tokyo, Tokyo 113, Japan; and ${ }^{\ddagger}$ Institute of Medical Science, St. Marianna \\ University School of Medicine, Kanagawa 216, Japan
}

\begin{abstract}
The HBx gene of hepatitis B virus has been shown to induce hepatic tumors in transgenic mice and is implicated in hepatocarcinogenesis in human hepatitis $B$ virus infection. To further characterize the role of $\mathbf{H B x}$ gene in carcinogenesis, we established mouse fibroblast cell lines in which the expression of HBx gene could be controlled by glucocorticoid hormone and examined the effect of $\mathrm{HBx}$ gene expression on cell growth in vitro. Along with the expression of $\mathrm{HBx}$ gene, most cells in the $G_{0} / G_{1}$ phase moved into the $S$ phase in $24 \mathrm{~h}$, and the cell cycle progressed further toward $48 \mathrm{~h}$. Induction of DNA synthesis was also demonstrated by bromo-deoxyuridine labeling analysis. These results indicate that HBx gene has a function to trigger the synthesis of cellular DNA and suggest that HBx gene may play a role in hepatocarcinogenesis in human infection by driving deregulated cell cycle progression. (J. Clin. Invest. 1994. 94:44-49.) Key words: mitogenic activity - hepatocarcinogenesis $\bullet$ inducible gene $\cdot$ dexamethasone
\end{abstract}

\section{Introduction}

The association of hepatitis $\mathrm{B}$ virus $(\mathrm{HBV})^{1}$ infection with hepatocellular carcinoma (HCC) is well documented and has been the focus of research over the past two decades $(1,2)$. However, the mechanism of hepatocarcinogenesis is still unclear despite the number of studies on integrated HBV genomes and adjacent host sequences $(3,4)$. These have failed to show an association of HBV integrants with activation of protooncogenes or inactivation of antioncogenes.

Recently, one of the four genes encoded by $\mathrm{HBV}$, the $\mathrm{HBx}$ gene, has been found to be a viral transactivator (5). Since then, a variety of genes has been shown to be activated by $\mathrm{HBx}$ protein, including viral genes such as the SV40 early region, human immunodeficiency virus long terminal repeat, Rous sarcoma virus, and $\mathrm{HBV}$ itself $(6,7)$, as well as cellular genes

Address correspondence to Kazuhiko Koike, M.D., First Department of Internal Medicine, Faculty of Medicine, University of Tokyo, 7-3-1 Hongo, Bunkyo-ku, Tokyo 113, Japan.

Received for publication 3 September 1993 and in revised form 22 February 1994.

1. Abbreviations used in this paper: $\mathrm{BrdU}$, bromo-deoxyuridine; $\mathrm{HBV}$, hepatitis B virus; HCC, hepatocellular carcinoma; MMTV, mouse mammary tumor virus; RT-PCR, reverse transcription PCR.

J. Clin. Invest.

(C) The American Society for Clinical Investigation, Inc.

0021-9738/94/07/0044/06 \$2.00

Volume 94, July $1994,44-49$ such as c-fos, c-myc, and major histocompatibility class I genes (8-10). Activating such a broad spectrum of genes, HBx gene is implicated in carcinogenesis as one of the causative factors (11). In fact, HBx gene has been shown to induce liver cancer in transgenic mice (12), and HBx gene products have been shown to be expressed in HCC tissues more frequently than in the surrounding liver $(13,14)$. In in vitro studies, however, it is still controversial whether or not $\mathrm{HBx}$ gene has transforming ability (15-17). In this study, we established mouse cell lines in which the expression of HBx gene could be controlled by the use of hormone and investigated the function of $\mathrm{HBx}$ gene in cell growth control and neoplastic transformation.

\section{Methods}

Plasmid construction. Plasmid pMTVHBx was constructed from plasmids pMTVE1A (18) and pSVXORF (19). In pSVXORF, the open reading frame of the HBx gene from HBV genome (subtype adr) (20) is located downstream of SV40 early promoter with modification of sequences in front of the initiation codon from TTTCC to AGAGC to improve the efficiency of translation (This modification was designed by Dr. I. Saito, Institute of Medical Science, University of Tokyo) (21). After introducing XhoI linker at StuI site of pSVXORF which lies 20bp upstream of the $\mathrm{HBx}$ initiation codon, the resulting plasmid pSVXXhoI was double-digested with XhoI and EcoRI and ligated with the large fragment of pMTVE1A, which was also digested with XhoI in combination with EcoRI (Fig. 1). In the final plasmid pMTVHBx, the $\mathrm{HBx}$ gene open reading frame was under the control of mouse mammary tumor virus (MMTV) long terminal repeat and was followed by processing signals of SV40.

Cell culture and DNA transfection. NIH3T3 cells obtained from the American Type Culture Collection (Rockville, MD) were grown in DME (Gibco Laboratories, Grand Island, NY) supplemented with $10 \%$ FCS (Gibco Laboratories) to confluence. Cells were trypsinized and replated into $10-\mathrm{cm}$ dishes. On the following day, pMTVHBx or control plasmid was transfected together with pRSVneo plasmid (10:1 ratio) into $5 \times 10^{5}$ NIH3T3 cells by the calcium phosphate method. Selection in medium containing geneticin (G418; Gibco Laboratories) at a concentration of $500 \mu \mathrm{g} / \mathrm{ml}$ was started $24 \mathrm{~h}$ later. After $2 \mathrm{wk}$ in the selection medium, positive clones were isolated.

DNA preparation and PCR method. Cells grown in 6-well dishes were rinsed with phosphate-buffered saline ( $\mathrm{pH} 7.4)$ and incubated with $100 \mu \mathrm{g} / \mathrm{ml}$ of proteinase $\mathrm{K}$ for $45 \mathrm{~min}$ at $56^{\circ} \mathrm{C}$ in $500 \mu \mathrm{l}$ of K-buffer $(50$ $\mathrm{mM} \mathrm{KCl}, 20 \mathrm{mM}$ Tris/ $\mathrm{Cl}, 2.5 \mathrm{mM} \mathrm{MgCl} 2, \mathrm{pH} \mathrm{8.3)}$ ). After inactivating proteinase $\mathrm{K}$ by heating at $95^{\circ} \mathrm{C}$ for $10 \mathrm{~min}, 10 \mu \mathrm{l}$ of preparation was used for PCR detection. For the PCR method, a set of 20-mer oligonucleotides (S1, GGAGTAGTAGTGATCTACCG; X3, CATGGAGACCACCGTGAACG) was chosen as primers in the sequences of plasmid pMTVHBx over SV40 intervening sequences.

$R N A$ preparation and reverse transcription $P C R(R T-P C R)$ method. Cells were harvested with trypsin, and RNA was extracted from cells as described by Chomczynski and Sacchi (22). RNA was analyzed by RT-PCR as described previously (23), using X3 and S1 primers. Then, samples were analyzed by electrophoresis in $2 \%$ agarose gel and in some cases were subjected to Southern blotting. For normalization of the amounts of RNA, $\beta$-actin mRNA was determined using RT-PCR. 


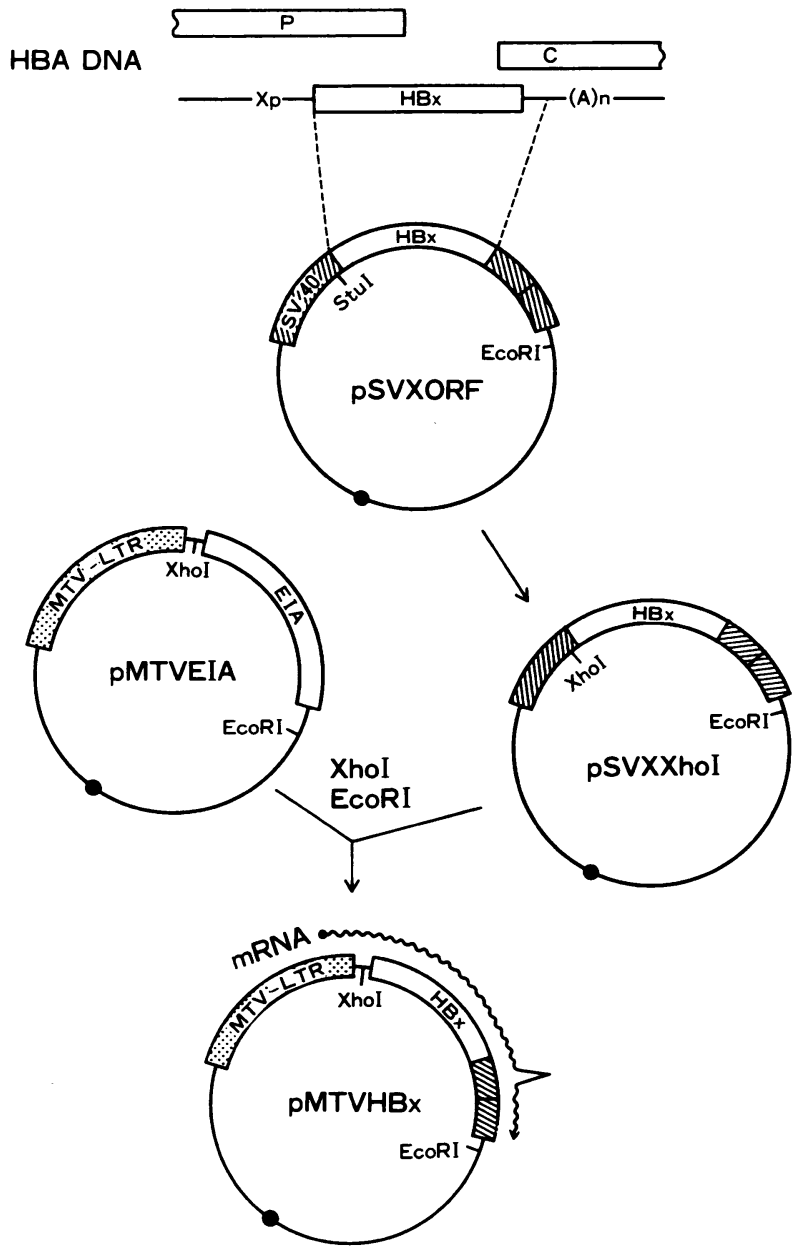

Figure 1. Construction of the plasmid pMTVHBx. An Xhol site was introduced into a plasmid pSVXORF (19) in which the HBx gene open reading frame was under the control of SV40 regulatory sequences. The resulting plasmid pSVXXhoI was then digested with XhoI in combination with EcoRI and ligated with a larger fragment of pMTVEIA which was also double-digested with XhoI and EcoRI. In the final plasmid pMTVHBx, HBx gene was under the control of MMTV long terminal repeat, with a modification of sequences in front of the initiation codon from TTTCC to AGAGC.

A pair of primers (ACT1, CAGGTCATCACCATTGGCAATGAG; ACT2, CAGCACTGTGTTGGCGTACAGGTC) was set in the coding sequence of mouse $\beta$-actin gene. Reverse transcriptase reaction and PCR amplification were performed so that the PCR reaction was within the logarithmic phase.

Southern blotting. Amplified products were separated in $2 \%$ agarose gel and transferred to a nylon membrane (Nytran; Schleicher \& Schuell, Dassel, Germany). The membrane was then hybridized with a 20-mer oligonucleotide probe (X2, AGCCTCCTAGTACAAAGACC) positioned between $\mathrm{X} 3$ and $\mathrm{S} 1$ primers which was labeled with digoxigenin labeling kit (Boehringer Mannheim Corp., Indianapolis, IN).

Western blotting. Cells were lysed in sample buffer $(62.5 \mathrm{mM}$ Tris/ $\mathrm{HCl}, 2 \% \mathrm{SDS}, 5 \% \beta$-mercaptoethanol ). $20 \mu \mathrm{g}$ of protein was separated in $15 \%$ SDS/polyacrylamide gel and transferred to a nitrocellulose filter (Schleicher \& Schuell). Then, the filter was reacted with anti-HBx rabbit serum (19) and detected with biotinylated anti-rabbit IgG in combination with avidin-biotinylated horseradish peroxidase complex (Vector Labs, Inc., Burlingame, CA). Visualization was done using an ECL kit (Amersham Intl., Buckinghamshire, UK).

Nuclear labeling index. Cells were grown to confluent monolayers
Table I. Saturation Density of Cell Lines

\begin{tabular}{lc}
\hline Cell lines & Saturation density* \\
\hline MTX1-2 & $14.1 \pm 2.8$ \\
MTX1-7 & $10.6 \pm 2.2$ \\
MTX1-14 & $12.5 \pm 3.2$ \\
MTX1-16 & $11.1 \pm 1.5$ \\
MTX1-21 & $10.1 \pm 0.8$ \\
MTX2-3 & $9.9 \pm 2.6$ \\
MTX2-4 & $13.1 \pm 1.8$ \\
MTX2-7 & $10.5 \pm 2.8$ \\
MTX2-8 & $13.5 \pm 2.1$ \\
MTX2-10 & $9.8 \pm 2.5$ \\
MTX2-12 & $10.8 \pm 3.1$ \\
neo-2 & $10.2 \pm 2.0$ \\
neo-3 & $12.2 \pm 3.7$ \\
neo-6 & $12.1 \pm 2.8$ \\
neo-8 & $11.1 \pm 3.1$ \\
neo-9 & $9.8 \pm 1.7$ \\
NIH3T3 & $7.4 \pm 4.4$ \\
\hline
\end{tabular}

* Average $\pm \mathrm{SD}(n=5), \times 10^{-4}$ cells $/ \mathrm{cm}^{2}$.

in Lab-Tek cell culture chambers (Nunc, Inc., Naperville, IL) and then were growth-arrested by incubating in DME containing $0.1 \%$ FCS for $48 \mathrm{~h}$. Bromo-deoxyuridine (BrdU) was then added with or without dexamethasone $\left(10^{-6} \mathrm{M}\right)$ and incubated for $60 \mathrm{~min}$. After $24 \mathrm{~h}$, the cells were fixed with cold acetone for $15 \mathrm{~min}$ and stained with antiBrdU antibody using the Cell Proliferation kit (Amersham Intl.).

Flow cytometry. A total of $2 \times 10^{5}$ cells was plated to 6-cm dishes in DME containing $0.1 \%$ FCS and synchronized in a quiescent state by incubating for $48 \mathrm{~h}$. Cells were then incubated for appropriate hours with or without addition of dexamethasone $\left(10^{-6} \mathrm{M}\right)$, harvested, and resuspended in dimethyl sulfoxide-sucrose buffer. After being stained with propidium iodide, cells were analyzed by FACScan ${ }^{\circledR}$ (Becton Dickinson \& Co., Mountain View, CA) with the CellFIT program.

\section{Results}

Isolation of NIH3T3 cells expressing HBx gene in response to dexamethasone. Among 42 clones which were G418-selected after cotransfection with pMTVHBx and pRSVneo, 41 clones were found to be pMTVHBx positive by screening with the PCR method. These clones were then seeded into two sets of 24-well microtiter plates, and only one set of cultures was treated with dexamethasone at a concentration of $10^{-6} \mathrm{M}$. After incubation for $24 \mathrm{~h}$, cells with or without dexamethasone stimulation were harvested and treated for RNA extraction. Then, inducibility of HBx gene was examined by the RT-PCR method, and 11 out of 41 clones tested were selected and designated as MTX cells. Most clones expressed HBx gene irrespective of the presence of dexamethasone. Five control NIH3T3 clones were also selected after cotransfection with pUC18 and pRSVneo. Plasmid pMTVAd12, pMTVE1A, or pMTVE1B (18) was also cotransfected to NIH3T3 cells with pRSVneo, and several clones were obtained as controls in the same way as MTX clones.

Saturation density of MTX cell lines. Table I shows the saturation density of MTX cell lines cultivated in the absence of dexamethasone in DME with 10\% FCS. While MTX cell lines had a slightly higher saturation density than parental 


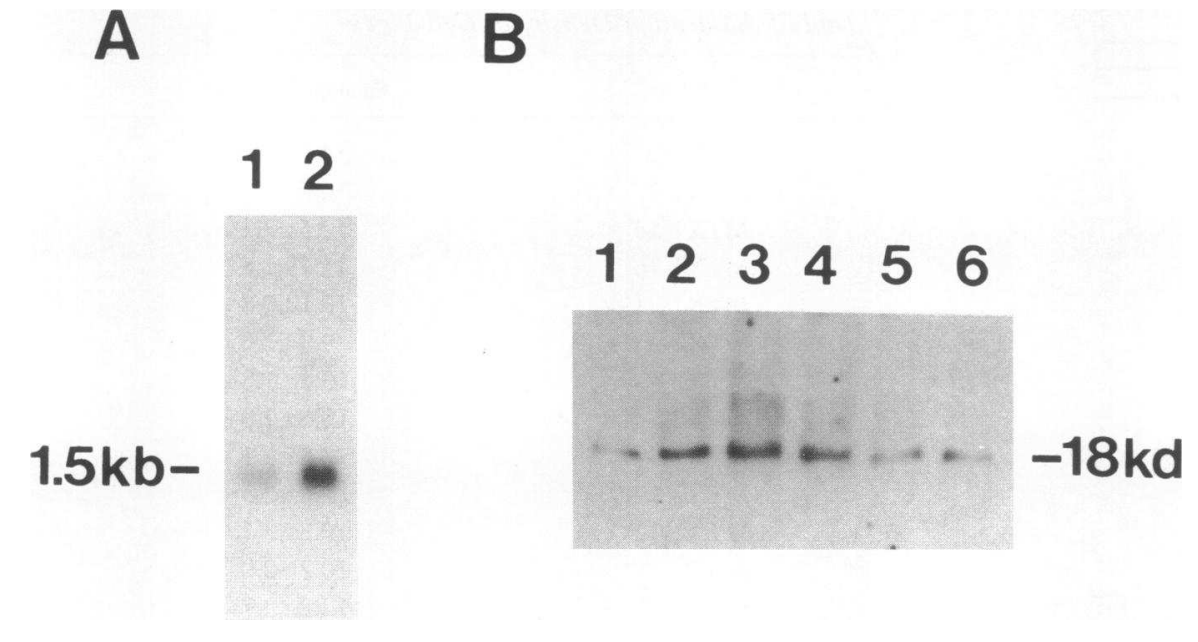

Figure 2. Expression of HBx gene after stimulation with corticosteroid. Dexamethasone was added at time 0 to a cell line with inducible HBx gene, MTX1-2, at a final concentration of $10^{-6} \mathrm{M}$, and total RNA or protein was subjected to analysis at the time indicated. $(A)$ Northern blotting. HBx-specific transcripts of the expected size, $1.5 \mathrm{~kb}$, increased dramatically at $6 \mathrm{~h}$ after the addition of dexamethasone (lane 2) compared with before stimulation (lane 1$)$. (B) Time course of HBx protein expression (Western blotting). The level of expression reached its peak at 6 $h$ after the addition of dexamethasone and returned to the basal level at $24 \mathrm{~h}$. Lane 1,0 $\mathrm{h}$; lane $2,3 \mathrm{~h}$; lane $3,6 \mathrm{~h}$; lane $4,12 \mathrm{~h}$; lane $5,18 \mathrm{~h}$; and lane $6,24 \mathrm{~h}$.

NIH3T3 cells, clonal NIH3T3 cell lines (neo series) also showed almost the same density as MTX cells, suggesting that relatively well growing NIH3T3 cells were selected as clonal cells in the process of G418 selection. Cultivation of these MTX cell lines in the presence of $10^{-6} \mathrm{M}$ dexamethasone resulted in a slight increase in saturation density by 1.1-1.4-fold.

Inducible expression of $H B x$ gene in MTX cells. Expression of HBx gene was examined in MTX cell lines (Fig. $2 A$ ). Six lines of MTX series showed marked induction of HBx gene expression after dexamethasone stimulation, while the remaining five lines had only a slight increase in HBx gene expression. The kinetics of induction of $\mathrm{HBx}$ gene expression was then analyzed by Western blotting on MTX1-2 cells which were grown to confluency in DME with $10 \%$ FCS. The expression of $\mathrm{HBx}$ protein began to increase as early as $3 \mathrm{~h}$ after the addition of dexamethasone, reached its peak in $6 \mathrm{~h}$, and returned to the basal level after $24 \mathrm{~h}$ (Fig. $2 \mathrm{~B}$ ).

Cell cycle progression of MTX cells after treatment with dexamethasone. To determine the effect of $\mathrm{HBx}$ gene expression on the induction of cellular DNA synthesis in MTX cells, 11 lines of MTX cells and control cell lines were cultivated in two sets of Lab-Tek chambers (Nunc, Inc.) and maintained in medium containing $0.1 \%$ FCS for $48 \mathrm{~h}$. One set of chambers was labeled with BrdU for $1 \mathrm{~h}$ at this time, while the other set
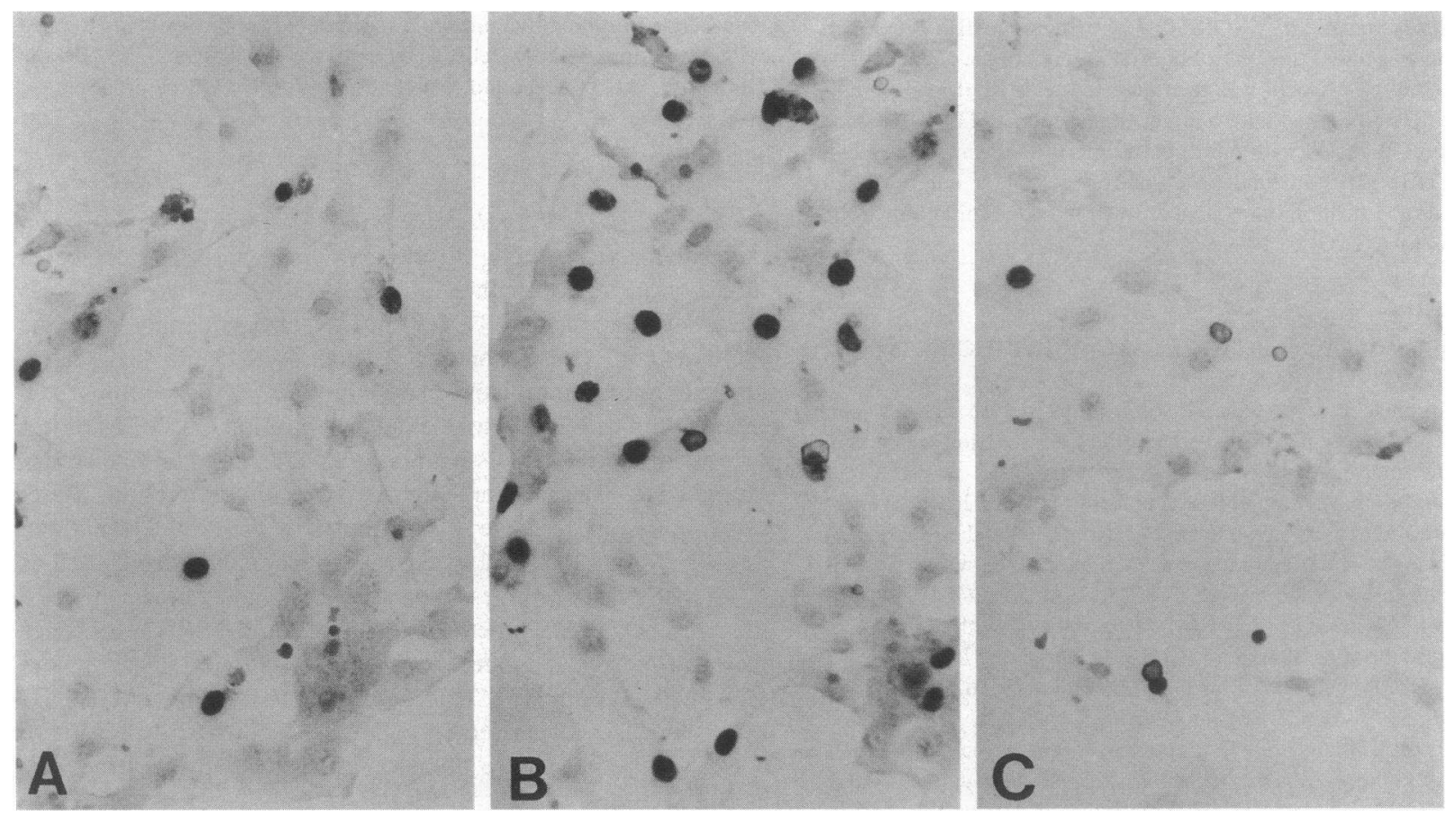

Figure 3. Induction of DNA synthesis in quiescent MTX cells by treatment with dexamethasone. MTX1-2 cells or control NIH3T3/neo-2 clonal cells were grown in monolayers in Lab-Tek culture chambers, and the medium was replaced with DME with $0.1 \%$ FCS. After a 48-h incubation, the cells were exposed to BrdU with or without dexamethasone at a concentration of $10^{-6} \mathrm{M}$ and stained with anti-BrdU antibody. A, MTX1-2 without dexamethasone; $B$, MTX1-2 with dexamethasone; $C$, NIH 3T3/neo-2 with dexamethasone. 
Table II. Stimulation of DNA Synthesis with Dexamethasone $(D E X)$ in Cell Lines

\begin{tabular}{|c|c|c|c|c|}
\hline \multirow[b]{2}{*}{ Cell lines } & \multicolumn{2}{|c|}{ HBx expression levels* } & \multicolumn{2}{|c|}{$\begin{array}{l}\text { Percentage of fraction of } \\
\text { cells synthesizing DNA }\end{array}$} \\
\hline & $\operatorname{DEX}(-)$ & $\operatorname{DEX}(+)$ & $\operatorname{DEX}(-)$ & $\operatorname{DEX}(+)$ \\
\hline MTX1-2 & 5 & 22 & 12 & $37^{8}$ \\
\hline MTX1-21 & 3 & 15 & 5 & $23^{8}$ \\
\hline MTX2-12 & 3 & 12 & 4 & $19^{8}$ \\
\hline MTX2-4 & 1.5 & 10 & 2 & $10^{8}$ \\
\hline MTX2-8 & 2 & 8 & 3 & $10^{8}$ \\
\hline MTX1-7 & 1 & 8 & 3 & $8^{8}$ \\
\hline MTX2-10 & 4 & 6 & 5 & 7 \\
\hline MTX1-16 & 2 & 2 & 2 & 2 \\
\hline MTX2-3 & 1 & 2 & 2 & 1 \\
\hline MTX1-14 & 1.5 & 2 & 1 & 2 \\
\hline MTX2-7 & 1 & 1 & 2 & 2 \\
\hline neo-2 & & & 2 & 2 \\
\hline neo-3 & & & 1 & 2 \\
\hline neo-6 & & & $<1$ & $<1$ \\
\hline neo-8 & & & 1 & 1 \\
\hline neo-9 & & & $<1$ & $<1$ \\
\hline E1B-1 & & & 1 & 1 \\
\hline E1B-3 & & & $<1$ & $<1$ \\
\hline E1B-7 & & & 1 & 2 \\
\hline E1B-10 & & & $<1$ & $<1$ \\
\hline E1B-18 & & & 2 & 2 \\
\hline E1A-5 & & & 5 & $41^{8}$ \\
\hline E1A-6 & & & 2 & $32^{8}$ \\
\hline E1A-9 & & & 5 & $15^{\S}$ \\
\hline
\end{tabular}

* Relative levels of HBx gene expression before (DEX(-)) or $6 \mathrm{~h}$ after the addition of DEX $(\operatorname{DEX}(+))$ as determined by Northern blotting. Expression levels are normalized using $\beta$-actin mRNA as control. ${ }^{\ddagger}$ Percentage of labeled nuclei in 500 nuclei counted (average of triplicated experiments). ${ }^{8}$ Increases from DEX $(-)$ values are statistically significant $(P<0.01)$ by Chi square test.

was labeled for $1 \mathrm{~h}$ after $24 \mathrm{~h}$ of incubation with dexamethasone at a concentration of $10^{-6} \mathrm{M}$. Labeled cells were then stained with anti-BrdU monoclonal antibody and processed for visualization. Photographs of representative cell lines, MTX1-2 and neo-2, are shown in Fig. 3. The percentage of labeled cells increased significantly after dexamethasone induction of $\mathrm{HBx}$ gene in MTX1-2 cells, while no increase was observed in control neo- 2 cells. The results for all the cell lines are summarized in Table II. In six of the MTX cell lines which had high levels of $\mathrm{HBx}$ gene expression with dexamethasone stimulation, the percentage of labeled nuclei in the untreated cultures was 2$12 \%$ and increased to $8-37 \%$ after dexamethasone stimulation, while in the remaining five cell lines the percentage increased very slightly, which is consistent with the low basal level and only slight induction of $\mathrm{HBx}$ gene expression in these cell lines. In five control cell lines, NIH3T3/neo series, no increase of labeled nuclei was observed after the addition of dexamethasone. Among other control cell lines, cells with pMTVE1A plasmid (E1A cells) demonstrated increased DNA synthesis as described previously (24), while cells with pMTVE1B plasmid (E1B cells) showed no increase despite the induction of E1B gene expression with dexamethasone (Table II).
The progression of the cell cycle in MTX cell lines after the addition of dexamethasone was monitored by flow cytometry, as outlined in Methods. Results of representative cell lines are shown in Fig. 4. After $18 \mathrm{~h}$ of treatment, the number of MTX12 cells in the $S$ phase markedly increased with a concomitant decrease of cells in the $G_{0} / G_{1}$ phase. After $24 \mathrm{~h}$, most of the cells entered into the $S$ and $G_{2} / M$ phases, and the cell cycle progressed further toward $48 \mathrm{~h}$. In contrast, the majority of control neo- 3 line cells remained in the $G_{0} / G_{1}$ phase after the addition of dexamethasone (Fig. 4). Upon a single dose of dexamethasone addition, cell numbers of MTX cell lines doubled in $48 \mathrm{~h}$, while control cells showed only a slight increase (Fig. 5).

Tumorigenicity of MTX cells in nude mice. Morphologically, MTX cell lines did not show the phenotype of transformed cells. Then, we examined the tumorigenicity of $\mathrm{HBx}$-expressing cells in nude mice by inoculating nude mice with $2 \times 10^{6}$ cells. Because the expression of HBx gene in MTX cells was low without induction with dexamethasone, $100 \mu \mathrm{g}$ of dexamethasone was injected into nude mice intraperitoneally every day after the inoculation of cells (18). None of the MTX cells or control NIH3T3/neo cells induced tumors in $8 \mathrm{wk}$, while NIH3T3 cells transformed by the adenovirus 12 early region 1 under the same MMTV regulatory region (pMTVAd12) induced tumors in 3-4 wk.

\section{Discussion}

We established several mouse fibroblast lines (MTX cells) in which the expression of HBx gene was regulated by corticosteroid by use of the construct containing $\mathrm{HBx}$ gene under the control of the MMTV long terminal repeat. Dexamethasone induced DNA synthesis in these cell lines at the quiescent state, in $8-37 \%$ of the cell population depending on the cell lines, showing that the overexpression of $\mathrm{HBx}$ gene had mitogenic activity in vitro. Because cell lines with low levels of $\mathrm{HBx}$ gene expression did not show mitogenic activity, more than a threshold level of $\mathrm{HBx}$ gene expression may be necessary for the induction of DNA synthesis. While we used mRNA in comparing the levels of $\mathrm{HBx}$ gene expression among cell lines, we also demonstrated the induction of $\mathrm{HBx}$ gene expression in protein levels. Therefore, HBx mRNA levels presumably reflect the levels of $\mathrm{HBx}$ protein in these cell lines. As shown in Table II, mitogenic phenotype observed in MTX clones does not reflect random clonal variation. Moreover, since E1B cell clones, which were selected exactly in the same way as MTX clones, demonstrated dexamethasone-induced E1B gene expression but no induction of DNA synthesis, mitogenic activity observed in MTX cells is not a result of the selection method itself.

$\mathrm{HBx}$ gene expression had little effect on saturation density when the induction of $\mathrm{HBx}$ gene was conducted under the condition of cell confluency in culture with $10 \%$ FCS. This is probably due to contact inhibition of cell growth in ultimate confluency, since MTX cells were not fully transformed or tumorigenic. In addition, $\mathrm{HBx}$ protein and serum may use the same pathway for the induction of cell proliferation (17).

HBx gene of HBV, a viral transcriptional transactivator, has been implicated in hepatocarcinogenesis as a gene which has a function similar to oncogenesis-related genes (11). In the in vivo system, $\mathrm{HBx}$ gene has been shown to induce liver cancer in transgenic mice (12), and in humans frequent expression of HBx gene has been demonstrated in HCC tissues by immuno- 

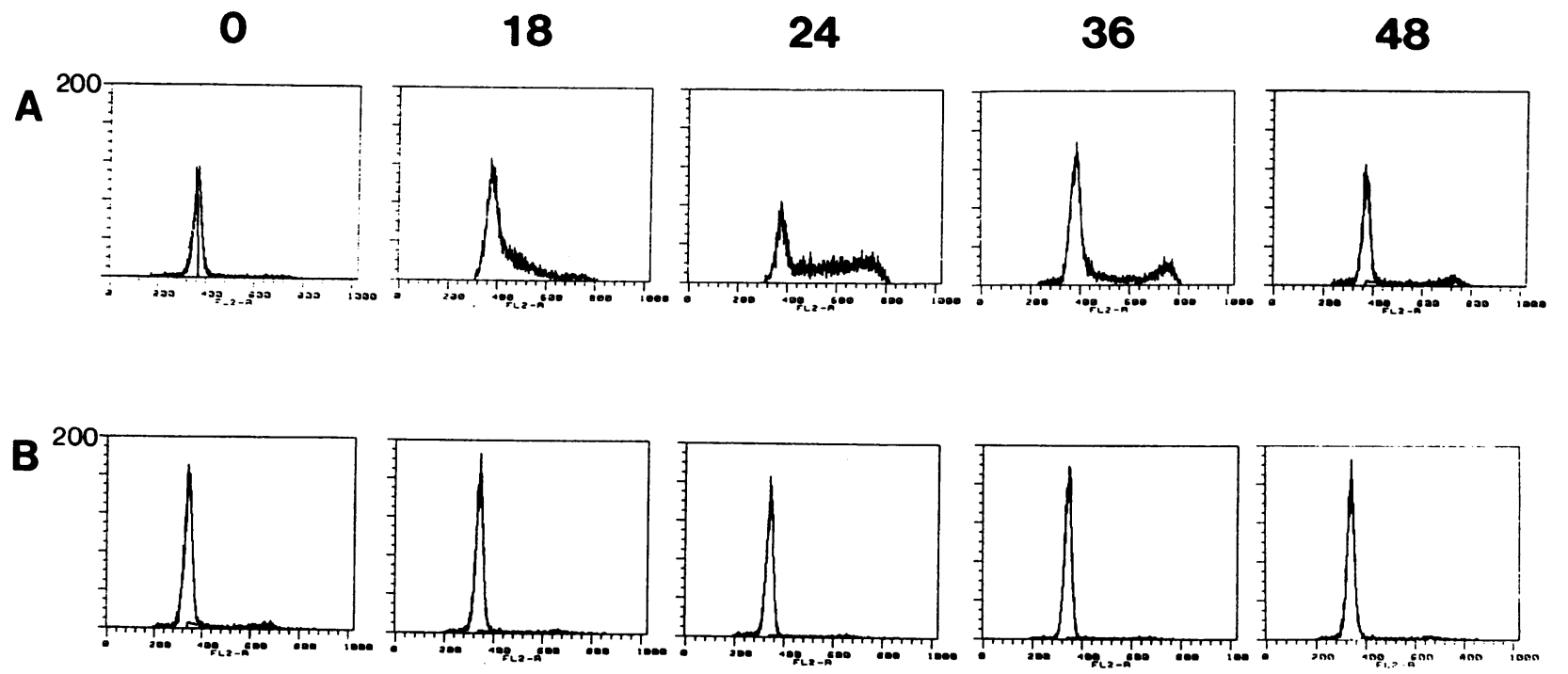

Figure 4. Cell cycle progression by HBx gene expression. HBx gene-introduced cell line, MTX1-2 (A), or clonal NIH3T3 cell line, 3T3/neo-3, as a control $(B)$ was stained with propidium iodide and analyzed by FACS $\$$ at an appropriate time after the addition of dexamethasone. Along with the expression of $\mathrm{HBx}$ gene, MTX cells entered into the $S$ and $\mathrm{G}_{2} / \mathrm{M}$ phases, while control cells remained quiescent. Numbers above each panel indicate hours after the addition of dexamethasone. Vertical axis, event number; horizontal axis, DNA content.

staining (13) or by the PCR method (14). However, it is still unclear whether or not $\mathrm{HBx}$ protein has oncogenic ability in cultured cells. It has been reported that $\mathrm{HBx}$ gene could transform NIH3T3 cells (16) or the immortalized mouse hepatocytes which were derived from mice transgenic for the SV40 T antigen gene (15). In contrast to such work, HBx gene-introduced cells showed no higher saturation density than control clonal NIH3T3 cells and no tumorigenicity in nude mice in our study. We also undertook colony formation assay in soft agar, resulting in no colony formation despite the stimulation of $\mathrm{HBx}$ gene

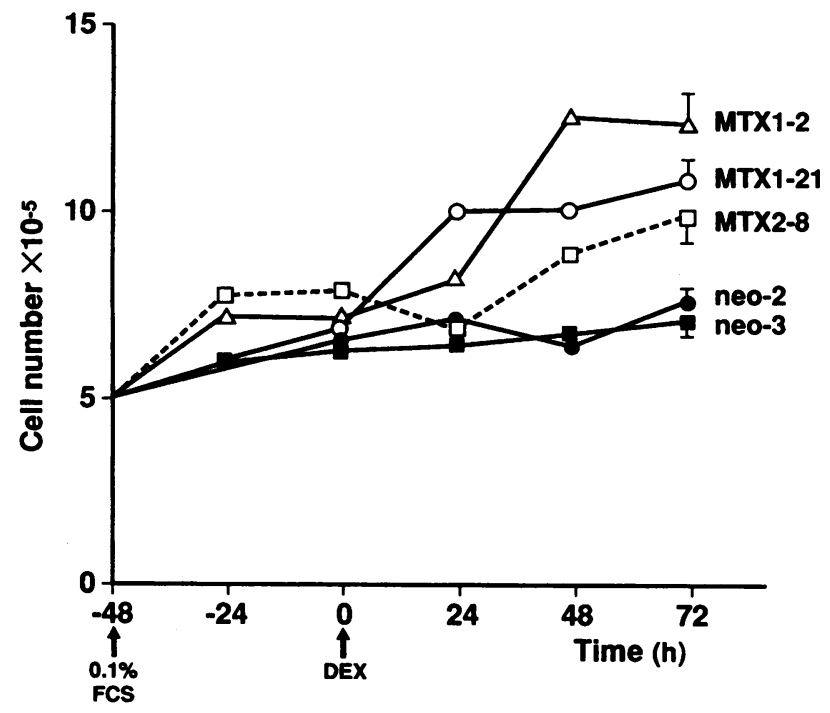

Figure 5. Increase of cell number in MTX cell lines after the induction of $\mathrm{HBx}$ gene expression. 500,000 cells were plated into $10-\mathrm{cm}$ dishes, and expression of $\mathrm{HBx}$ gene was stimulated after cultivating cells for $48 \mathrm{~h}$ in DME with $0.1 \%$ FCS. Cell number almost doubled in MTX cell lines in $48 \mathrm{~h}$ after the induction, while control NIH3T3 cell clones showed a very slight increase. $D E X$, dexamethasone. with daily addition of dexamethasone over soft agar. The soft agar assay, however, may not be suitable for the assessment of inducible genes, because a positive control cell line, which has adenovirus $12 \mathrm{E} 1$ oncogene under the same MMTV regulatory region, formed only a limited number of colonies in soft agar with dexamethasone despite its tumorigenicity in nude mice. In addition, without obtaining colony formation, we had no way to confirm whether or not the HBx gene was really induced with this method. Our results indicate that HBx gene has mitogenic activity but no oncogenic ability in the system using NIH3T3 cells. However, we should be careful in interpreting the discrepancy between our results and the results of Shirakata et al. (16) because the level of HBx gene expression may vary with different regulatory elements used, and there is a possibility that higher levels of HBx gene expression may lead to transformation of NIH3T3 cells, as described by Shirakata et al. (16).

It is interesting to note that nuclear oncogenes such as the adenovirus early region $1 \mathrm{~A}$ gene (24) or c-myc gene (25) have been known to possess mitogenic activity, which is the new property of HBx gene, and the mitogenic activity of these genes is considered to be closely related to their immortalizing abilities (24). In this sense, HBx gene might belong to nuclear-type oncogenes. Failing to transform NIH3T3 cells (17, this work) and being a transcriptional activator are consistent with $\mathrm{HBx}$ gene being a potential nuclear-type oncogene. On the other hand, transgenic mice studies have shown that growth factors such as TGF- $\alpha$ are potential oncoproteins when their expression is deregulated in vivo (26). In this context, although it is still not clear whether HBx protein could show mitogenic activity in normal hepatocytes as well as in immortalized fibroblasts, the mitogenic activity itself of HBx protein, which was shown in this study, may contribute to hepatocarcinogenesis in vivo. In fact, increased DNA synthesis is observed in hepatocytes with $\mathrm{HBx}$ gene expression in preneoplastic liver of transgenic mice (27). Alteration of cell growth cycle controls by $\mathrm{HBx}$ protein, resulting in continued cycling of cells under conditions which restrict the growth of normal cells, may be a major event in carcinogenesis in human HBV infection. 
Our data demonstrate that overexpression of $\mathrm{HBx}$ gene induces cell cycle progression in established culture cells. These HBx-expressing cells may be predisposed to transformation (28) and may be subject to secondary hits which are independent from the events provoked by HBx protein. It is interesting that recently $\mathrm{HBx}$ protein has been shown to use protein kinase $C$ pathways in acting as a transcriptional activator (17). Similar to a number of mitogens and growth factors, $\mathrm{HBx}$ protein may exhibit its mitogenic activity through this pathway. The MTX cell lines described here may be a good system to elucidate it and to further characterize complex events leading to transformation after the expression of $\mathrm{HBx}$ gene, such as identifying cofactors which are dimerized in functioning as transactivators (29).

\section{Acknowledgments}

We thank Dr. I. Saito for providing the plasmid pmoHBMX which is a parental plasmid of pSVXORF; Dr. T. Miyamura for helpful discussions; and Dr. S. Murakami for antibody.

This work was supported in part by Grant-in-Aid for Cancer Research from the Ministry of Education, Science and Culture, Japan.

\section{References}

1. Beasley, R. P., and L.-Y. Hwang. 1984. Epidemiology of hepatocellular carcinoma. In Viral Hepatitis and Liver Disease. G. N. Vyas, J. L. Dienstag, and J. H. Hoofnagle, editors. Grune \& Stratton, Inc., Orlando. 209-224.

2. Tiollais, P., C. Pourcel, and A. Dejean. 1985. The hepatitis B virus. Nature (Lond.). 317:489-495.

3. Tokino, T., S. Fukushige, T. Nakamura, T. Nagaya, T. Muritsu, K. Shiga, N. Aoki, and K. Matsubara. 1987. Chromosomal translocation and inverted duplication associated with integrated hepatitis B virus in hepatocellular carcinomas. J. Virol. 61:3848-3854.

4. Rogler, C. E., M. Sherman, C.-Y. Su, D. A. Shafritz, J. Summers, T. B. Shows, A. Henderson, and M. Kew. 1985. Deletion in chromosome 11p associated with a hepatitis B integration site in hepatocellular carcinoma. Science (Wash. DC). 230:319-322.

5. Twu, J.-S., and R. H. Schloemer. 1987. Transriptional transactivating function of hepatitis B virus. J. Virol. 61:3448-3453.

6. Seto, E., T.-S. B. Yen, B. M. Peterlin, and J.-H. Ou. 1988. Transactivation of the human immunodeficiency virus long terminal repeat by the hepatitis $B$ virus X protein. Proc. Natl. Acad. Sci. USA. 85:8286-8290.

7. Colgrove, R., G. Simon, and D. Ganem. 1989. Transcriptional activation of homologous and heterologous genes by the hepatitis $B$ virus $x$ gene product in cells permissive for viral replication. J. Virol. 63:4019-4026.

8. Twu, J.-S., M.-Y. Lai, D.-S. Chen, and W. S. Robinson. 1993. Activation of protooncogene c-jun by the X protein of hepatitis B virus. Virology. 192:346350 .

9. Balsano, C., M. L. Avantagiatti, G. Natoli, E. De Marzio, H. Will, M. Perricaudet, and M. Levrero. 1991. Full-length and truncated versions of the hepatitis B virus $\mathrm{x}$ protein transactivate the c-myc protooncogene at the transcriptional level. Biochem. Biophys. Res. Commun. 176:985-992.
10. Zhou, D.-X., A. Tarabouloos, J.-H. Ou, and T. S. B. Yen. 1990. Activation of class I major histocompatibility complex gene expression by hepatitis B virus. J. Virol. 64:4025-4028.

11. Wollersheim, M., U. Debelka, and P. H. Hofschneider. 1988. A transactivating function encoded in the hepatitis $B$ virus $x$ gene is conserved in the integrated state. Oncogene. 3:545-552.

12. Kim, C.-M., K. Koike, I. Saito, T. Miyamura, and G. Jay. 1991. HBx gene of hepatitis B virus induces liver cancer in transgenic mice. Nature (Lond.). 351:317-320.

13. Wang, W., W. T. London, and M. Feitelson. 1991. Hepatitis B $x$ antigen in hepatitis B virus carrier patients with liver cancer. Cancer Res. 51:4971 -4977.

14. Diamantis, I. D., C. E. McGandy, T.-J. Chen, Y.-F. Liaw, F. Gudat, and L. Bianchi. 1992. Hepatitis B x-gene expression in hepatocellular carcinoma. J. Hepatol. 15:400-403.

15. Seifer, M., M. Hohne, S. Schaefer, and W. H. Gerlich. 1991. In vitro tumorigenicity of hepatitis B virus DNA and HBx protein. J. Hepatol. 13:S61S65.

16. Shirakata, Y., M. Kawada, Y. Fujiki, H. Sano, M. Oda, K. Yaginuma, M. Kobayashi, and K. Koike. 1989. The $x$ gene of hepatitis $B$ virus induced growth stimulation and tumorigenic transformation of mouse NIH3T3 cells. Jpn. J. Cancer Res. 80:617-621.

17. Kekule, A. S., U. Lauer, L. Weiss, B. Luber, and P. H. Hofschneider. 1993. Hepatitis B virus transactivator HBx uses a tumor promoter signalling pathway. Nature (Lond.). 361:742-745.

18. Koike, K., S. H. Hinrichs, K. J. Isselbacher, and G. Jay. 1989. Transgenic mouse model for human gastric cancer. Proc. Natl. Acad. Sci. USA. 86:56155619.

19. Koike, K., T. Akatsuka, and T. Miyamura. 1988. Characterization of hepatitis $B$ virus $x$ gene: in vitro translation of mRMA from COS-1 cells transfected with the $x$ gene. Virology. 163:233-235.

20. Fujiyama, A., A. Miyanohara, C. Nozaki, T. Yonayama, N. Ohtomo, and K. Matsubara. 1983. Cloning and structural analysis of hepatitis B virus DNA: subtype adr. Nucleic Acids Res. 11:4601-4610.

21. Kozak, M. 1984. Point mutations close to the AUG initiator codon affect the efficiency of translation of rat preproinsulin in vivo. Nature (Lond.). 308:241 246.

22. Chomczynski, P., and N. Sacchi. 1987. Single-step method of RNA isolation by acid guadinium thiocyanate-phenol-chloroform extraction. Anal. Biochem. 162:156-159.

23. Yotsuyanagi, H., S. lino, K. Koike, K. Yasuda, K. Hino, and K. Kurokawa. 1993. Duration of viremia in human hepatitis A viral infection as determined by polymerase chain reaction. J. Med. Virol. 40:35-38.

24. Braithwaite, A. W., B. F. Cheetham, P. Li, C. R. Parish, L. K. WaldronStevens, and A. J. D. Bellett. 1983. Adenovirus-induced alterations of the cell growth cycle: a requirement for expression of E1A but not of E1B. J. Virol. 45:192-199.

25. Armelin, H. A., M. C. S. Armelin, K. Kelly, T. Stewart, P. Leder, B. H. Cochran, and C. D. Stiles. 1984. Functional role for c-myc in mitogenic response to platelet-derived growth factor. Nature (Lond.). 310:655-660.

26. Lee, G. H., G. Merlino, and N. Fausto. 1992. Development of liver tumors in transforming growth factor $\alpha$ transgenic mice. Cancer Res. 52:5162-5170.

27. Koike, K., K. Moriya, S. Iino, H. Yotsuyanagi, Y. Endo, T. Miyamura, and K. Kurokawa. 1994. High level expression of hepatitis B virus HBx gene and hepatocarcinogenesis in transgenic mice. Hepatology. 19:810-819.

28. Finney, R. E., and J. M. Bishop. 1993. Predisposition to neoplastic transformation caused by gene replacement of H-rasl. Science (Wash. DC). 260:15241527.

29. Seto, E., P. J. Mitchell, and T.-S. B. Yen. 1990. Transactivation by the hepatitis B virus $x$ protein depends on AP-2 and other transcription factors. Nature (Lond.). 344:72-74. 